\title{
Predictive Effect of Social Achievement Goals and Classroom Incivility on Difficulties during Emotion Regulation
}

\author{
Nihan Sölpük Turhan ${ }^{1}$, Tuğba Yılmaz Bingöl ${ }^{1} \&$ Nihan Arslan ${ }^{1}$ \\ ${ }^{1}$ Fatih Sultan Mehmet University, Department of Educational Sciences, İstabul, Turkey \\ Correspondence: Nihan Sölpük Turhan, Fatih Sultan Mehmet University, Department of Educational Sciences, \\ İstabul, Turkey. E-mail: nsolpuk@fsm.edu.tr
}

Received: July 1, 2019

Accepted: September 24, 2019 Online Published: September 25, 2019

doi:10.5539/hes.v9n4p58

URL: https://doi.org/10.5539/hes.v9n4p58

\begin{abstract}
The aim of this study is to examine the predictive role of students' social achievement goals and classroom incivility levels in their emotion regulation skills. The study was conducted with 309 university students and used "Social Achievement Goal Scale", "The Difficulties in Emotion Regulation Scale" and "Classroom Incivility Scale" as data collection tools. The study was carried out with 309 university students in Turkey during 2016-2017 academic year $\left(1^{\text {st }}, 2^{\text {nd }}, 3^{\text {rd }}\right.$ and $4^{\text {th }}$ year students). The findings obtained from regression analysis revealed that social achievement goals and classroom incivility account $15 \%$ of total changes in the difficulties faced during emotion regulation. As for the sub goals of the study, it was found that "social achievement goals" mean score of females was higher than that of males; males had higher "classroom incivility" levels than females; and the mean score of females for "difficulties in emotional regulation" was higher than that of males. While no difference was found in "incivility" factor in terms of "age" variable, there were significant differences in "social achievement goals" and "the difficulties in emotional regulation" factors. Similarly, there was no significant difference in "social achievement goals" and "classroom incivility factors" in terms of "class year" variable, but a significant difference was found for "difficulties in emotion regulation" factor. In addition, the results did not reveal any significant differences in "social achievement goals" and "classroom incivility" factors according to "perceived parental attitude"; however, a significant difference was found in "the difficulties in emotional regulation" factor. The research findings were discussed within the framework of the related literature.
\end{abstract}

Keywords: difficulties in emotion regulation, structural equation modeling, regression, model analysis

\section{Introduction}

Emotions play important roles in making sense of people's opinions and actions; i.e understanding them. Emotional reactions to situations are beneficial when they help individuals achieve their goals; however, if they hinder the process, they might be useless, and even harmful. The ability to regulate emotions effectively is also a basic skill for healthy relationships (Cole, 2014). When emotion regulation skills are poorly developed or they lack for some reasons, normative emotional development might be delayed and psychopathology risk considerably increases (McLaughlin, Hatzenbuehler, Mennin \& Nolen-Hoeksema, 2011). When an emotional reaction does not work, emotional regulation (ER) can regulate this particular emotion so as to meet the needs of individuals in specific situations (Ochsner \& Gross, 2014).

Emotional regulation involves a variety of skills such as defining, understanding and accepting emotional experiences, controlling problematic impulsive behavior, and managing emotional reactions appropriately according to the prevailing conditions (Cole, Michel \& Teti, 1994; Gratz \& Roemer, 2004; Eisenberg \& Spinrad 2004; Linehan, 1993; Thompson 1994). These skills often improves with age (Ortega, 2009) and difficulties in emotion regulation can be observed throughout an individual's life. Individuals' failure to regulate their emotions often results in various types of disorders such as self-harm (Gratz \& Tull, 2010), personality disorder (Kaufmann et al., 2015), drug addiction (Dvorak et al., 2014), depression (Crowell et.al 2014) and attention deficit hyperactivity disorder (Mitchell et.al 2012).

According to Gross and John (2003), individuals use certain emotion regulation strategies (such as interpersonal relationships, problem solving etc.) in order to regulate their emotions in their daily lives. Since people are inevitably exposed to many emotional stimuli in their lives, they often have to apply such emotion regulation strategies (Davidson, 1998). For instance, people often prefer not to pay attention to potentially threatening 
stimuli (Langens \& Mörth, 2003), they can overcome their traumatic experiences by writing about them (Pennebaker \& Chung, 2007) or they would rather direct their anger to another object than the real object that causes this feeling; for instance they hit on a pillow when they are angry instead of the person who makes them angry (Bushman, Baumeister \& Phillips, 2001).

Two-factor model suggested by Gross and John (2003) was acknowledged as an emotion regulation theory. This model distinguishes between antecedent-focused strategies and response-focused strategies. Antecedent-focused strategies are based on cognitive reappraisal, which represents a specific skill that reappraises an existing situation in order to alter emotional mood of an individual (Gross, 2002). For instance, decision makers might reconsider potential consequences of a specific decision in order to change or minimize emotional effects of decision making before they make a risky decision. On the contrary, response-focused strategies is about a skill used to hide an emotion (Gross, 2002). For instance, decision makers may keep their "poker face" to hide their emotions while bluffing in a card game. Gross and John (2003) claimed that these two emotion regulation strategies are independent from each other and they might be adopted as a habit (as a personality trait) or momentarily (situation-specific).

Developmental studies show that babysitters might play an important role in helping children regulating their emotions (Southam-Gerow \& Kandell, 2002). Similarly, environmental studies revealed that natural places help people overcome their stress more quickly than urban areas (Van den Berg, Hartig \& Staats, 2007). People may increase, maintain or reduce positive and negative emotions during emotion regulation, which often results in different emotional reactions. These changes in reactions might imply how people experience and express their emotions (Gross, 1999). Experiences of emotional changes through emotion regulation may not help individuals reach or even get closer to their intended emotional state. Some emotion regulation strategies may even result in emotional consequences which, in fact, individuals hope to avoid (Wegner, Erber \& Zanakos, 1993).

Emotion regulation may fail in many ways; individuals may express undesired feelings although they do their best to avoid them. When people continuously fail to regulate their emotions, their psychology might be affected negatively. As mentioned earlier, chronic disorders due to emotional regulation contribute to all main psychopathy problems (Bradley, 2000; Kring \& Werner, 2004).

"Social achievement", one of the variables in this study, has a complex relationship with emotions. Such a relationship can trigger and sustain individuals' emotions or reduce academic motivation (Zhou, 2016). An individual may have a harmony with his feelings about the tasks and information related to himself, and he might set his own emotion-specific goals (Pekrun, Goetz, Titz \& Perry, 2002 p. 97) or goals may provoke emotions as a consequence of goal-seeking (Daniels et al., 2009). Similar to Ryan and Shim (2006), Mouratis and Sideridis (2009), who carried out a study that examined the relationship between social achievement goals and two indices of socio-emotional harmony through students' peer relationships and social skills, observed that social development goals are positively related to harmony results, social demonstration-avoid goal is negatively related to harmony, and social demonstration-approach goal is not related to any of them.

Ryan and Shim $(2006,2008)$ classify social achievement goals into three groups depending on how individuals define social competence. The first group involves individuals who define social competence through the criteria attributed to them. The individuals in this group sustain their social development goals and focus on establishing meaningful relationships with others and understanding their own point of view by establishing well-established relationships. The second group individuals define social competence through normative criteria and focus on achievement expectations. They are assumed to support social demonstration-approach goals, and achievement means popularity and social status for them. Finally, individuals who define social competence through normative standards but focus on avoiding negative social outcomes such as refusal and being mocked are believed to adopt social demonstration- avoid goals.

Ryan and Shim (2006), in their study examining the relationship between social achievement goals and emotional outcomes, found a positive relationship between social development goals, self-report about well-being, social efficacy and social harmony. They found that social demonstration goals produce less positive results. In addition, Ryan and Shim (2006) stated that social development goals are the only positive predictor of welfare (except autonomy), social efficacy and social harmony. Unlike social development goals, social demonstration - approach goals fail to predict any outcome, social demonstration-avoid goals negatively predict personal development, autonomy and social efficacy and positively predicted not only social anxiety but also positive relationships.

Some studies which show a positive relationship between social development goals and social-emotional results for university students (Horst, Finney, \& Barron, 2007) and primary school students (Mouratidis \& Sideridis, 
2009; Ryan \& Shim, 2008) also support these findings. In addition, Ryan and Shim (2008) studied "perceived social competence" and interestingly concluded that social demonstration--avoid goals are less harmonious when compared to social demonstration-approach goals because they are positively related only to anti-social behaviors of students.

One of the anti-social behaviors of students is classroom incivility. According to Feldmann (2001), classroom incivility can be defined as any action interfering a harmonious and collaborative learning environment. Coping with classroom incivility is important since it might affect both personal and academic development (Marini, 2009). Marini (2009) classifies main processes of incivility into two groups: from indirect to direct; and from reactive to proactive. In indirect incivility, negative actions are carried out secretly; and there are direct rude behaviors in direct incivility. As for the second group, proactive incivility involves unwanted behaviors aiming to reach a goal (such as stealing lesson notes), and reactive incivility involves behaviors aiming to retaliate an action (Marini, 2009). In other words, incivility has both attitudinal and behavioral dimensions. In this respect, incivility can be classified into two groups; intentional and unintentional incivility. Intentional incivility, just like proactive incivility, is planned to give harm (Marini, Polihronis \& Blackwell, 2010). Spreading rumors about a classmate is a good example for that type of incivility (Marini, 2009) because it aims to give harm to this individual. Unintentional incivility occurs due to carelessness and inconsiderateness rather than giving harm (Marini et.al 2010). For instance, when a student checks his/her e-mails from her smart phone during the lesson, this action does not aim to give harm; however, it might mean disrespect.

On the basis of the information from the literature mentioned above, the researchers thought that the variables of this study might be related to each other, and the relationship among them were examined accordingly. Although there are some studies in the literature which conclude that these three concepts are related to each other indirectly, no studies dealt with three concepts all together. This study tries to answer the following research questions by focusing on these three concepts, which affect individuals mentally, socially and cognitively.

The aim of this research is to predict university students' emotion regulation skills by their social achievement levels and incivility.

\section{Methodology}

This qualitative study used causal-comparative model, which a research model that examines cause-effect relationships that already exist or later emerge between variables. These studies aim to determine the causes and effects of the differences among people without interfering the prevailing conditions and study participants (Büyüköztürk, Çakmak, Akgün, Karadeniz \& Demirel, 2009).

\subsection{Participants}

The study was conducted with students attending the education faculty of a university in Turkey during 2016-2017 academic years. The participants were determined by using quota sampling method. In this sampling method, researchers predetermine a quota for sampling and when this quota is reached, sampling process ends (Gökçe, 1988). Table 1 below displays demographic information about the participants.

Table 1. Demographic Information about the Participants

\begin{tabular}{|c|c|c|c|c|c|c|c|}
\hline Options & & 1 & 2 & 3 & 4 & 5 & Total \\
\hline \multirow{4}{*}{ Gender } & & Female & Male & & & & \\
\hline & $n$ & 166 & 143 & & & & 309 \\
\hline & $\%$ & 53.7 & 46.3 & & & & 100 \\
\hline & & $18-20$ & $21-23$ & 24 and above & & & \\
\hline \multirow[t]{3}{*}{ Age ranges } & $n$ & 96 & 173 & 40 & & & 309 \\
\hline & $\%$ & 31.1 & 56.0 & 12.9 & & & 100 \\
\hline & & 1 st year & 2nd year & 3rd year & 4th year & & \\
\hline \multirow[t]{2}{*}{ Class Year } & $n$ & 100 & 27 & 118 & 64 & & 309 \\
\hline & $\%$ & 32.4 & 8.7 & 38.2 & 20.7 & & 100 \\
\hline \multirow{3}{*}{$\begin{array}{l}\text { Perceived Parental } \\
\text { Attitude }\end{array}$} & & Authoritarian & Democratic & Indifferent & Protective & Inconsistent & \\
\hline & $n$ & 20 & 108 & 70 & 93 & 18 & 309 \\
\hline & $\%$ & 6.5 & 35.0 & 22.6 & 30.1 & 5.8 & 100 \\
\hline
\end{tabular}

The study was carried out with 309 university students in Turkey during $2016-2017$ academic year $\left(1^{\text {st }}, 2^{\text {nd }}, 3^{\text {rd }}\right.$ and $4^{\text {th }}$ year students). Of these students, $166(53.7 \%)$ were female and $143(46.3 \% \%)$ male. When the age range 
of the participants is concerned, it is seen that the highest number of participants was in "21-23" age range. In addition, the most commonly "perceived parental attitude" was "democratic" one.

\subsection{Data Collection Tools}

The data collection tools used in this study are Difficulties in Emotion Regulation Scale, Social Achievement Goal Scale and Classroom Incivility Scale.

Difficulties in Emotion Regulation Scale: Developed by Kaufmann et.al (2016), Difficulties in Emotion Regulation Scale was adapted to Turkish by Öztabak et.al (2017). The original and Turkish form consists of 18 items. The adapted Turkish form was administered to 282 university students. The items are replied through a five-point Likert scale; almost never (1), sometimes (2), about half the time (3) most of the time (4) and almost always (5). The scale has no reverse items. Exploratory Factor Analysis was done. It was found that sampling size is sufficient to apply factor analysis. KMO was calculated as .829 and Barlett test $\chi 2$ value as 2022,785 ( $\mathrm{p}<$. 001). As for the construct validity of the scale, we can talk about a three-dimensioned structure, which accounts for $77,105 \%$ of total variance. Total internal consistency coefficient of the scale was calculated as .87 . According to Exploratory Factor Analysis, fit indices were found to be $(X 2=213,98, \mathrm{sd}=112, \mathrm{p}=.00, \mathrm{X} 2 / \mathrm{sd}=1.91)$ and fit index values were calculated as RMSEA $=.066, \mathrm{RMR}=.012, \mathrm{NFI}=.90, \mathrm{NNFI}=.93, \mathrm{CFI}=.94, \mathrm{IFI}=.94$, AG$\mathrm{FI}=.90, \mathrm{GFI}=.90$

Social Achievement Goal Scale: 22 -item Social Achievement Goals Orientation Scale, which was developed by Ryan and Hopkins (2003), was later revised into 13-item Social Achievement Goal Scale by Horst, Finney and Barron (2015). This scale was adapted to Turkish language by Arslan et.al (2017). Five-point Likert scale of the items in Social Achievement Goal Scale involves not at all true of me (1), sometimes true of me (2), partly true of me (3), fairly true of me (4) and very true of me (5) statements. There are no reverse items in the scale. Total internal consistency coefficient of the scale was found to be .68. Exploratory Factor Analysis was done. It was found that sampling size is sufficient to apply factor analysis. KMO was calculated as .726 and Barlett test $\chi^{2}$ value as $1272,522(\mathrm{p}<.001)$. As for the construct validity of the scale, we can talk about a three-dimensioned structure, which accounts for $54,32 \%$ of total variance. Total internal consistency coefficient of the scale was calculated as .68. According to Exploratory Factor Analysis, fit index was found to be $(\mathrm{X} 2 / \mathrm{sd}=2,36)$ and fit index values were calculated as RMSEA=. 07, $\mathrm{RMR}=.09, \mathrm{NFI}=.86, \mathrm{CFI}=.91, \mathrm{IFI}=.91$, AG- FI=.90, GFI=.94

Classroom Incivility Scale: Developed by Farrell, Provenzano, Spadafora, Marini and Volk (2015), Classroom Incivility Scale was adapted to Turkish language by Bingöl et.al (2017). Both English and Turkish form consists of 10 items. The replies to the items are given through a five-point Likert scale: never (1), rarely (2), sometimes (3), often (4), and almost always (5). The scale has no reverse items. Total internal consistency coefficient of the scale was found to be .81 . It was found that sampling size is sufficient to apply factor analysis. KMO was calculated as .818 and Barlett test $\chi 2$ value as $611,482(\mathrm{p}<.001)$. As for the construct validity of the scale, we can talk about a three-dimensioned structure, which accounts for 53,69 \% of total variance. Total internal consistency coefficient of the scale was calculated as .80. According to Exploratory Factor Analysis, fit index was found to be $(\mathrm{X} 2 / \mathrm{sd}=3,148)$ and fit index values were calculated as RMSEA=. 09, RMR=.07, NFI=. 89, CFI=.92, IFI=.92, AG- FI=.89, GFI=.93

\subsection{Data Analysis}

Independent Sampling t-test was applied in order to show whether students' "social achievement goals," "classroom incivility" and "difficulties in emotion regulation" differ according to "gender" variable.

One-way variance analysis was done to determine whether students' "social achievement goals," "classroom incivility" and "difficulties in emotion regulation" differ according to "age" variable. Scales with unfilled items were excluded from the analysis.

The data obtained was analyzed through multiple regression technique and structural equation modeling goodness of fit indices in order to determine to what extent "social achievement goals", "classroom incivility" account for "emotion regulation". Multiple regression analysis and stepwise regression analysis were performed to determine the predictors of Social Achievement Goals and Classroom Incivility. Structural equation modeling was performed to test the established model of the predicted variable Emotion Regulation. The significance of the obtained statistics was tested at .05 level. SPSS 21 and Amos software were used for data analysis purposes.

Regression analysis is basically dependent variable change in what first generation revealed that much of the rest of the arguments described by one of the data analysis techniques. Structural Equation Modeling, the second generation data analysis technique, provides an explanation of the modeling of relationships between variables. Structural equation modeling provides a systematic and comprehensive approach to a complex research problem 
in a single process by modeling the relationships between many dependent and independent variables (Anderson and Gerbing, 1988). In a multi-step model, direct effects can be detected by regression analysis, while indirect effects of variables are ignored. However, in structural equation modeling, each relationship level is evaluated simultaneously. Therefore, the results were compared by using two different analysis methods.

\subsection{Findings}

Table 2 below presents mean and standard deviation values for students' scores from "social achievement goals," "classroom incivility" and "difficulties in emotion regulation" factors. Social Achievement Goal Scale has the highest mean while Classroom Incivility Scale the lowest.

Table 2. Descriptive statistics of the variables

\begin{tabular}{llllllll}
\hline Scales & $\boldsymbol{n}$ & $\overline{\boldsymbol{X}}$ & $\boldsymbol{S S}$ & Max. & Min. & Skewness & Kurtosis \\
\hline 1-Social Achievement Goal & 309 & 2.81 & .505 & 4 & 2 & .21 & -.01 \\
2-Classroom Incivility & 309 & 1.84 & .610 & 5 & 1 & 1.67 & 4.32 \\
3-The Difficulties in Emotion Regulation & 309 & 2.59 & .548 & 5 & 1 & .56 & .24 \\
\hline
\end{tabular}

2.4.1 Evaluation of How Students' Social Achievement Goals, Classroom Incivility and Difficulties in Emotion Regulation Differ According To "Gender" Variable

The results of the T-test applied to examine how social achievement goals, classroom incivility and difficulties in emotion regulation differ according to gender are displayed in Table 3 below.

Table 3. Mean, standard deviation and $\mathrm{t}$ values for social achievement goals, classroom incivility and difficulties in emotion regulation according to gender factor

\begin{tabular}{lllllll}
\hline Variables & Gender & $\boldsymbol{n}$ & $\overline{\boldsymbol{X}}$ & $\boldsymbol{S S}$ & $\boldsymbol{t}$ & $\boldsymbol{p}$ \\
\hline \multirow{2}{*}{ 1-Social achievement goals } & Male & 143 & 2.86 & .53 & \multirow{2}{*}{1.55} & .12 \\
& Female & 166 & 2.77 & .48 & & \\
2-Classroom incivility & Male & 143 & 1.95 & .68 & & \\
& Female & 166 & 1.74 & .53 & -2.89 & .01 \\
3-Difficulties in emotion regulation & Male & 143 & 2.57 & .53 & & \\
$S D=307$ & Female & 166 & 2.60 & .56 & -.49 & .63 \\
& & & & & & \\
\hline
\end{tabular}

According to Table 3, social achievement goals mean score of females $\left(\mathrm{X}^{-}=2.86\right)$ is higher than that of males $\left(X^{-}=2.77\right)$; mean score for "classroom incivility" of males $\left(X^{-}=1.95\right)$ is higher than that of females $\left(X^{-}=1.74\right)$; and females' difficulties in emotion regulation mean score $\left(X^{-}=2.60\right)$ is higher than that of males $\left(X^{-}=2.57\right)$. According to the statistical data obtained in this study, there is not a significant difference for "social achievement goals" and "difficulties in emotion regulation" factors in terms of "gender" variable [p>.05]; but there is a significant difference in "classroom incivility" factor $[\mathrm{p}<.05]$.

2.4.2 Evaluation of Students' Social Achievement Goals, Classroom Incivility, and Difficulties in Emotion Regulation According To "Age” Variable

Table 4 displays the results of ANOVA, which was applied to evaluate "social achievement goals" and "classroom incivility" and "differences in emotion regulation" according to "age" variable. The results of one-way variance analysis are presented, which was done to show whether these variables are significantly different in terms of "age." 
Table 4. One-way Variance Analysis (ANOVA) results for social achievement goals, classroom incivility and difficulties in emotion regulation in terms of age

\begin{tabular}{llllllllll}
\hline \multicolumn{3}{c}{$n, X$ and SS values } & \multicolumn{1}{c}{ ANOVA results } \\
\hline Variables & Age Ranges & $\boldsymbol{n}$ & $\boldsymbol{X}$ & $\boldsymbol{S S}$ & K.T. & SD & K.O. & F & $\boldsymbol{p}$ \\
\hline 1-Social & $18-20$ & 96 & 2.92 & .51 & 1.81 & 2 & .91 & 3.61 & .03 \\
Achievement Goals & $21-23$ & 173 & 2.77 & .49 & 76.80 & 306 & .26 & & \\
& 24 and above & 40 & 2.73 & .55 & 78.60 & 308 & & & \\
2-Classroom & $18-20$ & 96 & 1.89 & .66 & .58 & 2 & .29 & .78 & .46 \\
Incivility & $21-23$ & 173 & 1.83 & .59 & 114.09 & 306 & .37 & & \\
& 24 and above & 40 & 1.75 & .59 & 114.67 & 308 & & & \\
3-Difficulties in & $18-20$ & 96 & 2.71 & .60 & 3.11 & 2 & 1.55 & 5.31 & .01 \\
Emotion Regulation & $21-23$ & 173 & 2.57 & .50 & 89.52 & 306 & .29 & & \\
& 24 and above & 40 & 2.38 & .57 & 92.62 & 308 & & & \\
\hline
\end{tabular}

According to the statistical data obtained in this study, there is not a significant difference for "classroom incivility" factor according to "age" variable [p>.05]; but a significant one for "difficulties in emotion regulation" and "social achievement goal" factors $[p<.05]$. Later, post-hoc analyses techniques were used to examine which age range caused these significant differences in "difficulties in emotion regulation" and "social achievement goals" factors.

First of all, Levene's test was used to analyze whether the variances of group distributions were homogenous or not. The results revealed homogenous variances [p>.05], and Scheffe multiple comparison tests was used accordingly. The reason why Scheffe test preferred in this study is that this test is sensitive to Alpha type error. Post-hoc Scheffe test showed a significant difference between "18-20" age range and " 24 and above" age range in terms of the variable "social achievement goals". In addition, a significant difference was found between "18-20" age range and "24 and above" age range according to "difficulties in emotion regulation".

2.4.3 Evaluation of Students' Social Achievement Goals, Classroom Incivility, and Difficulties in Emotion Regulation in Terms of "Class Year"

Table 5 displays the results of ANOVA, which was applied to evaluate "social achievement goals" and "classroom incivility" and "differences in emotion regulation" according to "class year" variable. The results of one-way variance analysis are presented, which was done to show whether these variables are significantly different in terms of "class year".

Table 5. One-way Variance Analysis (ANOVA) results for social achievement goals, classroom incivility and difficulties in emotion regulation in terms of class year

\begin{tabular}{llllllllll}
\hline \multicolumn{1}{c}{$n, X$ and SS values } & \multicolumn{8}{c}{ ANOVA results } \\
\hline Variables & Class year & $\boldsymbol{n}$ & $\boldsymbol{X}$ & $\boldsymbol{S S}$ & K.T. & SD & K.O. & $\mathbf{F}$ & $\boldsymbol{p}$ \\
\hline 1-Social & 1st year & 100 & 2.92 & .52 & 1.77 & 3 & .59 & 2.34 & .07 \\
Achievement Goals & 2nd year & 27 & 2.81 & .57 & 76.84 & 305 & .25 & & \\
& 3rd year & 118 & 2.76 & .47 & 78.610 & 308 & & & \\
2-Classroom & 4 th year & 64 & 2.73 & .52 & & & & & \\
Incivility & 1st year & 100 & 1.86 & .67 & .65 & 2 & .22 & .58 & .63 \\
& 2nd year & 27 & 1.69 & .65 & 114.02 & 306 & .37 & & \\
3-Difficulties in & 3rd year & 118 & 1.85 & .58 & 114.67 & 308 & & & \\
Emotion Regulation & 4 th year & 64 & 1.84 & .55 & & & & & \\
& 2n year & 100 & 2.73 & .57 & 5.04 & 2 & 1.68 & 5.85 & .01 \\
& 2nd year & 27 & 2.50 & .51 & 87.58 & 306 & .29 & & \\
& 3rd year & 118 & 2.60 & .52 & 92.62 & 308 & & & \\
\hline
\end{tabular}

According to the statistical data obtained in this study, there is not a significant difference for "social achievement goal" and "classroom incivility" factors in terms of "class level" [p>.05]; but a meaningful one for "difficulties in emotion regulation" factor. Later, post-hoc analyses techniques were used to examine which "class year" caused this significant difference in "difficulties in emotion regulation" factor.

First of all, Levene's test was used to analyze whether the variances of group distributions were homogenous or 
not. The results revealed homogenous variances [p>.05], and Scheffe multiple comparison tests was used accordingly. The reason why Scheffe test preferred in this study is that this test is sensitive to Alpha type error. Post-hoc Scheffe test showed a significant difference between $1^{\text {st }}$ year and $4^{\text {th }}$ year groups in terms of the variable "difficulties in emotion regulation"

3.4.4 Evaluation of Students' Social Achievement Goals, Classroom Incivility, and Difficulties in Emotion Regulation in Terms of "Perceived Parental Attitude" Variable

Table 6 displays the results of ANOVA, which was applied to evaluate "social achievement goals," "classroom incivility," and "differences in emotion regulation" according to "perceived parental attitude." The results of one-way variance analysis are presented, which was done to show whether these variables are significantly different in terms of "perceived parental attitude."

Table 6. One-way Variance Analysis (ANOVA) results for social achievement goals, classroom incivility and difficulties in emotion regulation in terms of perceived parental attitude

\begin{tabular}{|c|c|c|c|c|c|c|c|c|c|}
\hline \multicolumn{5}{|c|}{$n, X$ and $S S$ values } & \multicolumn{5}{|c|}{ ANOVA results } \\
\hline Variables & $\begin{array}{l}\text { Perceived } \\
\text { Parental Attitude }\end{array}$ & $n$ & $X$ & $S S$ & K.T. & SD & K.O. & $\mathbf{F}$ & $p$ \\
\hline \multirow{5}{*}{$\begin{array}{l}\text { 1-Social } \\
\text { Achievement Goals }\end{array}$} & Authoritarian & 20 & 2.82 & .47 & .71 & 3 & .18 & .70 & .60 \\
\hline & Democratic & 108 & 2.80 & .53 & 77.90 & 305 & .26 & & \\
\hline & Indifferent & 70 & 2.79 & .51 & 78.61 & 308 & & & \\
\hline & Protective & 93 & 2.80 & .46 & & & & & \\
\hline & Inconsistent & 18 & 3.00 & .63 & & & & & \\
\hline \multirow{5}{*}{$\begin{array}{l}\text { 2-Classroom } \\
\text { İncivility }\end{array}$} & Authoritarian & 20 & 2.00 & .78 & 1.73 & 2 & .43 & 1.16 & .33 \\
\hline & Democratic & 108 & 1.80 & .60 & 112.94 & 306 & .37 & & \\
\hline & Indifferent & 70 & 1.84 & .54 & 114.67 & 308 & & & \\
\hline & Protective & 93 & 1.80 & .58 & & & & & \\
\hline & Inconsistent & 18 & 2.06 & .82 & & & & & \\
\hline \multirow{5}{*}{$\begin{array}{l}\text { 3-Difficulties in } \\
\text { Emotion Regulation }\end{array}$} & Authoritarian & 20 & 2.51 & .39 & 4.50 & 2 & 1.13 & 3.89 & .00 \\
\hline & Democratic & 108 & 2.47 & .54 & 88.19 & 306 & .29 & & \\
\hline & Indifferent & 70 & 2.56 & .49 & 92.62 & 308 & & & \\
\hline & Protective & 93 & 2.72 & .58 & & & & & \\
\hline & Inconsistent & 18 & 2.85 & .59 & & & & & \\
\hline
\end{tabular}

According to the statistical data obtained in this study, there is not a significant difference in "social achievement goal" and "classroom incivility" factors in terms of "perceived parental attitude" [p>.05]; but a meaningful one for "difficulties in emotion regulation" factor. Later, post-hoc analyses techniques were used to examine which "perceived parental attitude" caused this significant differences in "difficulties in emotion regulation" factor.

First of all, Levene's test was used to analyze whether the variances of group distributions were homogenous or not. The results revealed homogenous variances [p>.05], and Scheffe multiple comparison tests was used accordingly. The reason why Scheffe test preferred in this study is that this test is sensitive to Alpha type error. Post-hoc Scheffe test showed a significant difference between "democratic" and "protective" parental attitude in terms of the variable "difficulties in emotion regulation"

\subsection{The Findings of Multi Regression Analyses}

3.5.1 The Findings of Multi Regression Analyses for Students' Social Achievement Goals, Classroom Incivility and Difficulties in Emotion Regulation

Table 7. Multi Regression Analysis results for social achievement goals, classroom incivility and difficulties in emotion regulation

\begin{tabular}{lccccc}
\hline Difficulties in Emotion Regulation & $B$ & $S H B$ & $\beta$ & $t$ & $p$ \\
\hline Constant & 1.25 & .17 & & 7.23 & .00 \\
1-Social Achievement Goal & .38 & .06 & .35 & 6.66 & .00 \\
2-Classroom Incivility & .15 & .05 & .16 & 3.07 & .00 \\
$n=309, R=.41, R^{2}=.17, F=31.08, p<.05$ & & & & \\
\hline
\end{tabular}

Table 7 displays the results of multi regression analysis, which was applied to determine how students' "social 
achievement goals" and "classroom incivility" predict "difficulties in emotion regulation". According to the table, students' social achievement goals, and classroom incivility meaningfully predict $17 \%[\mathrm{R}=.41, \mathrm{R} 2=.17, \mathrm{~F}=31.08$, $\mathrm{p}<.01]$ of difficulties in emotion regulation; and $8 \%$ are predicted by other variables.

3.5.2 Multi Regression Analysis Results for Students' Social Achievement Goals, Classroom Incivility, Perceived Parental Attitudes, and Difficulties in Emotion Regulation

Table 8. Multi Regression Analysis results for students' social achievement goals, classroom incivility, perceived parental attitudes and difficulties in emotion regulation

\begin{tabular}{llcccc}
\hline Difficulties in Emotion Regulation & $B$ & $S H B$ & $\beta$ & $t$ & $p$ \\
\hline Constant & 0.986 & .18 & & 7.23 & .00 \\
1-Social Achievement Goal & .37 & .06 & .34 & 6.66 & .00 \\
2-Classroom incivility & .15 & .05 & .16 & 3.07 & .00 \\
3- Perceived Parental Attitude & .10 & .03 & .19 & 3.76 & .00 \\
$n=309, R=.45, R^{2}=.21, F=26.31, p<.05$ & & & & \\
\hline
\end{tabular}

Table 8 displays the results of multi regression analysis which was applied to determine how students' social achievement goals, classroom incivility and perceived parental attitude predict difficulties in emotion regulation. According to the table, students' social achievement goals, classroom incivility and perceived parental attitude account for $21 \%$ of "difficulties in emotion regulation" $[\mathrm{R}=.45, \mathrm{R} 2=.21, \mathrm{~F}=26.31, \mathrm{p}<.01]$ and $79 \%$ can be explained by other variables.

\subsubsection{Findings of Structural Equation Modeling Goodness of Fit Indices}

This model was about the relationships between university students' (here the participants) "difficulties in emotion regulation", "social achievement goals", and "classroom incivility". The goodness of fit for this theoretical model was presented through GFI, AGFI, RMSEA, $\chi^{2}$ ve $\chi^{2} / \mathrm{df}$ rates. CFI goodness of fit was calculated as 0.70 , RMSEA value as 0.08 and $\chi 2 / \mathrm{df}$ rate as 3.385 . When this value is lower than 5 , it means there is a good fit between observed co-variance matrices.

Table 9. Structural Equation Modeling Goodness of Fit Parameters for students' social achievement goals, classroom incivility and difficulties in emotion regulation

\begin{tabular}{ll}
\hline Fit Parameters & Coefficient \\
\hline RMSEA & 0.08 \\
$D f$ & 772 \\
$\chi^{2}$ & 2613.039 \\
$\chi^{2} / d f$ & 3.385 \\
\hline
\end{tabular}

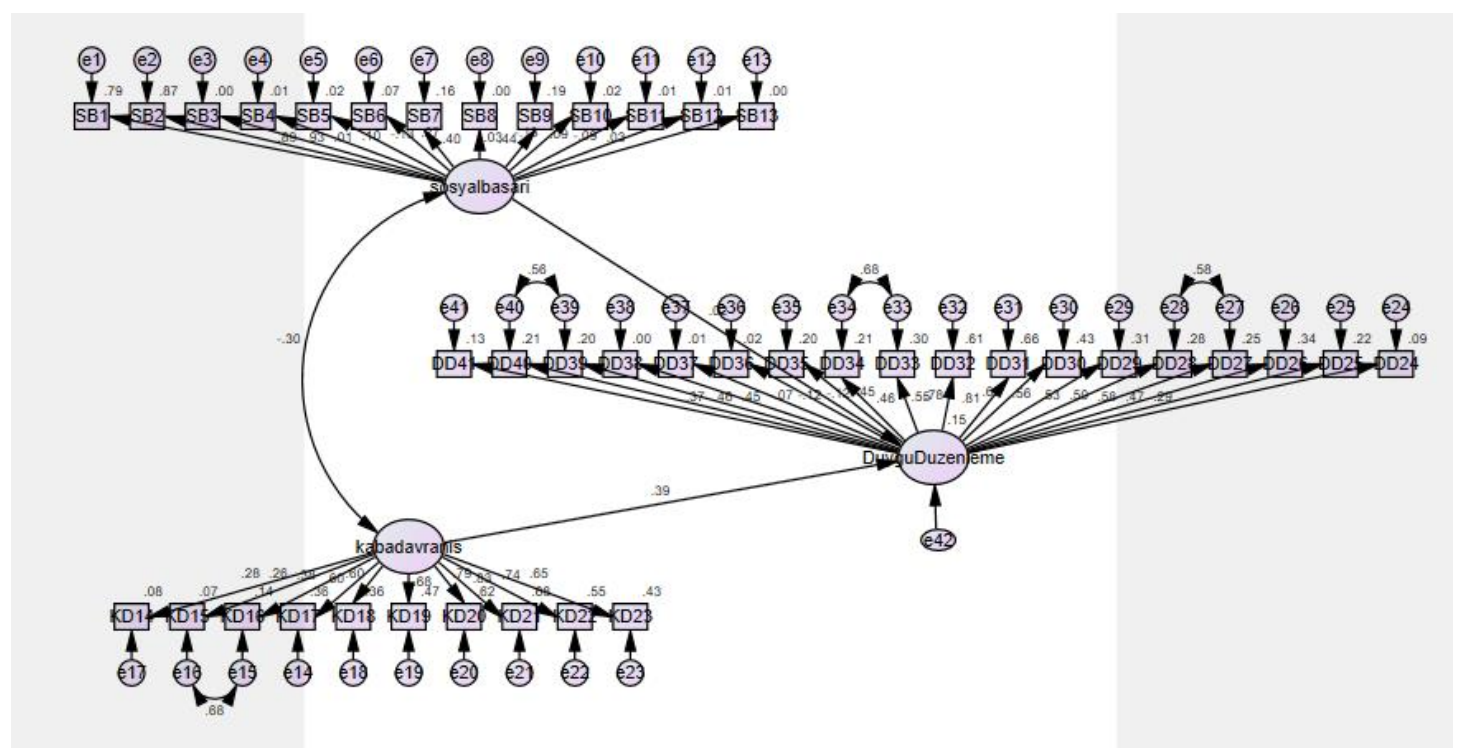

Figure 1. Structural Equation Modeling for Students' Social Achievement Goals, Classroom Incivility and Difficulties in Emotion Regulation 
According to Figure 1, standardized regression coefficient for "social achievement goals" and "differences in emotion regulation" was calculated as 0.39 ; for "classroom incivility" and "difficulties in emotion regulation as 0.02 ; and for "classroom incivility" and "social achievement goals" as -0.30 . "Social achievement goals" and "classroom incivility" account for $15 \%$ of total change of "difficulties in emotion regulation".

\section{Discussion - Conclusion and Recommendations}

According to the results of the Structural Equation Modeling, "social achievement goals" and "classroom incivility" account $15 \%$ of the total changes in "difficulties in emotion regulation".

"Classroom incivility" negatively affects academic and personal development. Such behaviors also affect in-class interaction and prevent shareholders of education process from reaching pre-determined educational objectives in the long term. Therefore; this phenomenon should be focused on during puberty and young adulthood, when social bonds are established. If certain precautions are taken in advanced regarding classroom incivility, it might be possible to prevent some negative consequences such as post-puberty behavior disorders and potential difficulties in emotion regulation (Farrell et.al, 2016). As a result of the research, average scores of men's incivility behavior were higher than women's. In adolescence time, it can be a very important to handle rough behaviors before they become more serious. As such, it is increasingly important to focus on class consciousness, as it can affect both academic and personal development (Marini, 2009). Classroom incivility behavior has the potential to disrupt the learning environment and teaching capabilities of the institution (Feldmann, 2001). Educators can often ignore incivility behavior in order to have more teaching time and believe that these behaviors can be lost on their own (Farrell,Provenzano,Spadpfora,Marini \& Volk, 2016).

It was found that the average scores of women's social achievement goals were higher than those of men. Studies based on personal differences between boys and girls in terms of social achievement goals are included in the literature. Research findings support studies indicating that female students perceive the classroom learning environment more positively than male students, significant gender-related differences (Waxman and Huang, 1997), most of the female students in elementary, middle, and high school classes ). The average score of difficulties in the regulation of emotion of women was found to be higher than men. In studies, women report that almost all types of emotion regulation strategies are used more than men. These strategies include reassessment, problem solving, acceptance and social support. In addition, girls are higher on effortful control than boys (Nolen-Hoeksema, 2012). These findings are consistent with the results of the study.

Generally speaking, "emotion regulation" refers to a specific skill used to identify, understand and accept emotional experiences, to control problematic impulsive behaviors and to manage emotional reactions by taking prevailing conditions into consideration (Eisenberg \& Spinrad, 2004). In this respect, individuals encountering difficulties while regulating their emotions find it difficult to control their impulsive behaviors and manage emotional reactions, which might lead to incivility too. The related research revealed a relationship between "difficulties in emotion regulation" and drug addiction, depression, behavioral problems, attention deficit hyperactivity disorder, anxiety, post-traumatic stress disorder and borderline personality disorder (Drovak et .al 2014; Cappadocia et al. 2009; Weiss et al. 2013). Thus, it is clear that "difficulties in emotion regulation" are among the main reasons of comorbidity cases.

Identity development is related to social achievement, academic motivation and performance, and emotion regulation (Jankovski, 2013). The findings of our study revealed that "difficulties in emotion regulation" predicted "social achievement". Besides, such difficulties might result in "classroom incivility" as well. Indeed, communicating with friends and obeying classroom rules are examples of social behavior (Wentzel, 2000). A social achievement goal involves social efficacy development and improved social relationships and social skills (i.e friendship and developing insights about how to establish good relationships; Shim, Cho \& Wang, 2013). Therefore; when individuals face difficulties in emotion regulation, they may encounter problems in their friendship relationships, which is likely to lead to incivility and affect social achievement negatively.

Those who can regulate their emotions and find a good balance between their emotions and opinions can understand others' emotions and opinions, which will help them to be successful in their daily lives (Goroshit \& Hen, 2014). Individuals who can regulate and manage their emotions have higher levels of empathy and life satisfaction levels, and they confide in their social efficacy more (Schunk, 2005). All these findings are consistent with the findings of our study. Lazarus and Folkman (1984) state that the individuals with an ability to manage their emotions are less likely to label "encounters" as threatening and more likely to adopt effective overcoming strategies. The use of such strategies will affect "incivility" behavior and those who can regulate their emotions will practice incivility less. The research showed that many problems that occur during childhood and puberty periods are related to "difficulties in emotion regulation". Thus, improving emotion regulation skills 
of teenagers and young adults might contribute to social achievement, and it might be possible to reduce classroom incivility, too.

It is possible to teach and improve emotion regulation skill (Pool \& Qualter, 2012). Thus, families and teachers should try hard to improve emotion regulation skill levels of their students and create opportunities to support their developments. There are some studies concluding that perceived parental attitudes affect emotion regulation (Niditch \& Varela, 2012). In this respect, adopting democratic and supportive parental attitudes instead of critical one is important in solving puberty problems. Among the practices aiming to improve empathy skill levels of students in schools are group counselling, classroom counselling, group psychological counselling activities and family training sessions. In addition, it is possible to implement practices at university level focusing on emotion regulation and strategies to express and manage emotions. Especially, academicians working at psychology and psychological counselling departments can design and implement practices aiming to increase emotion regulation skills, or they might supervise some senior students to help new comers. Helping individuals to improve their emotion regulation skills as well as to express and manage their emotions will prevent a considerable number of behavioral problems. This study was conducted with university students, so the findings might be supported by using different sampling groups too. Among the limitations of the study, data were collected only from the scales. Since scales were used in the study, the results of the study were limited to the scale items. Also limitation of the study include that lack of target resources in data collection process. In addition, another limitation of the study was the inability to control environmental conditions during the data collection process. Qualitative and experimental studies can contribute to the results of the research.

\section{References}

Bradley, S. J. (2000). Affect Regulation and the Development of Psychopathology. New York, NY: Guilford Press.

Bushman, B. J., Baumeister, R. F., \& Phillips, C. M. (2001). Do people aggress to improve their mood? Catharsis beliefs, affect regulation opportunity, and aggressive responding. Journal of Personality and Social Psychology, 81, 17-32. https://doi.org/10.1037/0022-3514.81.1.17

Büyüköztürk, Ş., Çakmak, E. K., Akgün, Ö. E., Karadeniz, Ş., \& Demirel, F. (2009). Bilimsel araştırma yöntemleri (4. bask1) (Scientific research methods (4th edition)). Ankara: Pegem Press.

Cappadocia, M., Desrocher, M., Pepler, D., \& Schroeder, J. H. (2009). Contextualizing the neurobiology of conduct disorder in an emotion dysregulation framework. Clinical Psychology Review, 29, 506-518. https://doi.org/10.1016/j.cpr.2009.06.001

Cole, P. M. (2014). Moving ahead in the study of the development of emotion regulation. International Journal of Behavioral Development, 38(2), 203-207. https://doi.org/10.1177/0165025414522170

Cole, P. M., Michel, M. K., \& Teti, L. O. D. (1994). The development of emotion regulation and dysregulation: A clinical perspective. Monographs of the society for research in child development, 59(23), 73-102. https://doi.org/10.2307/1166139

Crowell, S. E., Baucom, B. R., Yaptangco, M., Bride, D., Hsiao, R., McCauley, E., \& Beauchaine, T. P. (2014). Emotion dysregulation and dyadic conflict in depressed and typical adolescents: Evaluating concordance across psychophysiological and observational measures. Biological psychology, 98, 50-58. https://doi.org/10.1016/j.biopsycho.2014.02.009

Daniels, L. M., Stupnisky, R. H., Pekrun, R., Haynes, T. L., Perry, R. P., \& Newall, N. E. (2009). A longitudinal analysis of achievement goals: From affective antecedents to emotional effects and achievement outcomes. Journal of Educational Psychology, 101, 948-963. https://doi.org/10.1037/a0016096

Davidson, R. J. (1998). Affective style and affective disorders: Perspectives from affective neuroscience. Cognition and Emotion, 12, 307-330. https://doi.org/10.1080/026999398379628

Dvorak, R. D., Sargent, E. M., Kilwein, T. M., Stevenson, B. L., Kuvaas, N. J., \& Williams, T. J. (2014). Alcohol use and alcohol-related consequences: associations with emotion regulation difficulties. The American Journal of Drug and Alcohol Abuse, 40, 125-130. https://doi.org/10.3109/00952990.2013.877920

Eisenberg, N., \& Spinrad, T. L. (2004). Emotion-related regulation: sharpening the definition. Child Development, 75, 334-339. https://doi.org/10.1111/j.1467-8624.2004.00674.x

Farrell, A. H., Provenzano, D. A., Spadafora, N., Marini, Z. A., \& Volk, A. A. (2016). Measuring adolescent attitudes toward classroom incivility: Exploring differences between intentional and unintentional incivility. Journal of Psychoeducational Assessment, 34(6), 577-588. https://doi.org/10.1177/0734282915623446 
Farrell, A. H., Provenzano, D. A., Spadpfora, N., Marini, Z. A., \& Volk, A. A. (2016). Measuring adolescent attitudes toward classroom incivility: Exploring differences between intentional and unintentional incivility. Journal of Psychoeducational Assessment, 34(6), 577-588. https://doi.org/10.1177/0734282915623446

Feldmann, L. J. (2001). Classroom civility is another of our instructor responsibilities. College Teaching, 49, 137-140. https://doi.org/10.1080/87567555.2001.10844595

Goroshit, M., \& Hen, M. (2014). Does Emotional Self-efficaccy Predict Teachers' Self Efficacy and Empathy?. Journal of Education and Training Studies, 2(3), 26-32. https://doi.org/10.11114/jets.v2i3.359

Gökçe, B. (1988). Toplumsal bilimlerde araştırma. (Research in social sciences.) Ankara: Savaş Press.

Gratz, K. L., \& Roemer, L. (2004). Multidimensional Assessment of Emotion Regulation and Dysregulation: Development, Factor Structure, and Initial Validation of the Difficulties in Emotion Regulation Scale. Journal of Psychopathology and Behavioral Assessment, 26(1), 41-54. https://doi.org/10.1023/B:JOBA.0000007455.08539.94

Gratz, K. L., \& Tull, M. T. (2010). Emotion regulation as a mechanism of change in acceptance-and mindfulness-based treatments. Assessing mindfulness and acceptance processes in clients: Illuminating the theory and practice of change, Oakland, CA: New Harbinger Publications.

Gross, J. J. (1999). Emotion regulation: Past, present, future. Cognition and Emotion, 13, 551-573. https://doi.org/10.1080/026999399379186

Gross, J. J. (2002). Emotion Regulation: Affective, Cognitive, and Social Consequences. Psychophysiology, 39, 281-291. https://doi.org/10.1017/S0048577201393198

Gross, J. J., \& John, O. P. (2003). Individual differencesn in two emotion regulation processes: Implications for affect, relationships, and well-being. Journal of Personality and Social Psychology, 85, 348-362. https://doi.org/10.1037/0022-3514.85.2.348

Horst, S. J., Finney, S. J., \& Barron, K. E. (2007). Moving beyond academic achievement goal measures: A study of social achievement goals. Contemporary Educational Psychology, 32, 667-698. https://doi.org/10.1016/j.cedpsych.2006.10.011

Jankowski, P. (2013). Identity status and emotion regulation in adolescence and early adulthood. Polish Psychological Bulletin, 44, 288- 298. https://doi.org/10.2478/ppb-2013-0032

Kaufman, E. A., Xia, M., Fosco, G., Yaptangco, M., Skidmore, C. R., \& Crowell, S. E. (2016). The difficulties in emotion regulation scale short form (DERS-SF): validation and replication in adolescent and adult samples. Journal of Psychopathology and Behavioral Assessment, 38(3), 443-455. https://doi.org/10.1007/s10862-015-9529-3

Kring, A. M., \& Werner, K. H. (2004). Emotion regulation in psychopathology. In P. Philippot \& R. S. Feldman (Eds.), The regulation of emotion. NJ: Lawrence Erlbaum Associates, Inc.

Langens, T. A., \& Mörth, S. (2003). Repressive coping and the use of passive and active coping strategies. Personality and Individual Differences, 35, 461-473. https://doi.org/10.1016/S0191-8869(02)00207-6

Linehan, M. M. (1993). Cognitive behavioral therapy of borderline personality disorder. New York: Guilford Press.

Marini, Z. A. (2009). The thin line between civility and incivility: Fostering reflection and self-awareness to create a civil learning community. Collected Essays on Learning and Teaching, 2, 61-67. https://doi.org/10.22329/celt.v2i0.3204

Marini, Z. A., Polihronis, C., \& Blackwell, W. (2010). Academic in/civility: Co-constructing the foundation for a civil learning community. Collected Essays on Learning and Teaching, 3, 89-93. https://doi.org/10.22329/celt.v3i0.3245

McLaughlin, K. A., Hatzenbuehler, M. L., Mennin, D. S., \& Nolen-Hoeksema, S. (2011). Emotion dysregulation and adolescent psychopathology: A prospective study. Behaviour Research and Therapy, 49(9), 544-554. https://doi.org/10.1016/j.brat.2011.06.003

Mitchell, J. T., Robertson, C. D., Anastopolous, A. D., Nelson-Gray, R. O., \& Kollins, S. H. (2012). Emotion dysregulation and emotional impulsivity among adults with attention-deficit/hyperactivity disorder: results of a preliminary study. Journal of Psychopathology and Behavioral Assessment, 34(4), 510-519. https://doi.org/10.1007/s10862-012-9297-2 
Mouratidis, A. A., \& Sideridis, G. D. (2009). On social achievement goals: Their relations with peer acceptance, classroom belongingness, and perceptions of loneliness. Journal of Experimental Education, 77, 285-307. https://doi.org/10.3200/JEXE.77.3.285-308

Niditch, L. A., \& Varela, R. E. (2012). Perceptions of parenting, emotional self-efficacy, and anxiety in youth: test of a mediational model. In Child \& Youth Care Forum, 41(1), 21-35. https://doi.org/10.1007/s10566-011-9150-x

Nolen-Hoeksema, S. (2012). Emotion regulation and psychopathology: The role of gender. Annu. Rev. Clin. Psychol, 8, 161-187. https://doi.org/10.1146/annurev-clinpsy-032511-143109

Ochsner, K., \& Gross, J. (2014). The neural bases of emotion and emotion regulation: A valuation perspective. In J. J. Gross (Ed.), Handbook of emotion regulation (2nd ed., pp. 23-42). New York, NY: Guilford Press.

Orgeta, V. (2009). Specificity of age differences in emotion regulation. Aging and Mental Health, 13(6), 818-826. https://doi.org/10.1080/13607860902989661

Pekrun, R., Goetz, T., Titz, W., \& Perry, R. (2002). Academic Emotions in Students' Self-Regulated Learning and Achievement: A Program of Qualitative and Quantitative Research. Educational Psychologist, 37(2), 91-105. https://doi.org/10.1207/S15326985EP3702_4

Pennebaker, J. W., \& Chung, C. K. (2007). Expressive writing, emotional upheavals, and health. In H. Friedman \& R. Silver (Eds.), Handbook of health psychology (pp. 263-284). New York: Oxford University Press.

Pool, D. L., \& Qualter, P. (2012). Improving emotional intelligence and emotional self-efficacy through a teaching intervention for university students. Learning and Individual Differences, 22, 306-312. https://doi.org/10.1016/j.lindif.2012.01.010

Ryan, A. M., \& Shim, S. S. (2006). Social achievement goals: The nature, and consequences of different orientations toward social competence. Personality and Social Psychology Bulletin, 32, 1246-1263. https://doi.org/10.1177/0146167206289345

Ryan, A. M., \& Shim, S. S. (2008). An exploration of young adolescents' social achievement goals and social adjustment in middle school. Journal of Educational Psychology, 100, 672-687. https://doi.org/10.1037/0022-0663.100.3.672

Schunk, D. H. (2005). Commentary on self-regulation in school contexts. Learning and Instruction, 15(2), 173-177. https://doi.org/10.1016/j.learninstruc.2005.04.013

Shim, S. S., Cho, Y., \& Wang, C. (2013). Classroom goal structures, social achievement goals, and adjustment in middle school. Learning and Instruction, 23, 69-77. https://doi.org/10.1016/j.learninstruc.2012.05.008

Southam-Gerow, M. A., \& Kendall, P. C. (2002). Emotion regulation and understanding: Implications for child psychopathology and therapy. Clinical Psychology Review, 22, 189-222. https://doi.org/10.1016/S0272-7358(01)00087-3

Thompson, R. A. (1994). Emotion regulation: A theme in search of a definition. In N. A. Fox (Ed.), The development of emotion regulation: Biological and behavioral considerations. Monographs of the Society for Research in Child Development (pp. 25-52). Chicago: University of Chicago Press. https://doi.org/10.1111/j.1540-5834.1994.tb01276.x

Van den Berg, A. E., Hartig, T., \& Staats, H. (2007). Preference for nature in urbanized societies: Stress, restoration, and the pursuit of sustainability. Journal of Social Issues, 63, 79-96. https://doi.org/10.1111/j.1540-4560.2007.00497.x

Waxman, H. C., \& Huang, L. S-Y. (1997). Classroom instruction and learning environment differences between effective and ineffective urban elementary schools for African American students. Urban Education, 32(1), 7-44. https://doi.org/10.1177/0042085997032001002

Wegner, D. M., Erber, R., \& Zanakos, S. (1993). Ironic processes in the mental control of mood and mood-related thought. Journal of Personality and Social Psychology, 65, 1093-1104. https://doi.org/10.1037/0022-3514.65.6.1093

Weiss, N. H., Tull, M. T., Anestis, M. D., \& Gratz, K. L. (2013). The relative and unique contributions of emotion dysregulation and impulsivity to posttraumatic stress disorder among substance dependent inpatients. Drug and Alcohol Dependence, 128, 45-51. https://doi.org/10.1016/j.drugalcdep.2012.07.017

Wentzel, K. R. (2000). What is it that I'm trying to achieve? Classroom goals from a content perspective. 
Contemporary Educational Psychology, 25(1), 105-115. https://doi.org/10.1006/ceps.1999.1021

Zhou, M. (2016) University Students' Emotion During Online Search Task: A Multiple Achievement Goal Perspective. The Journal of Psychology, 150(5), 576-590. https://doi.org/10.1080/00223980.2016.1143797

\section{Copyrights}

Copyright for this article is retained by the author(s), with first publication rights granted to the journal.

This is an open-access article distributed under the terms and conditions of the Creative Commons Attribution license (http://creativecommons.org/licenses/by/4.0/). 